\title{
ANALYSIS OF MODULUS OF ELASTICITY OF SPRUCE BEAMS UNDER BENDING WITH AND WITHOUT FIBRE REINFORCEMENT
}

\author{
Krisztián Andor, Bertalan Bellovics \\ University OF SOPRON \\ Sopron, Hungary
}

(Received April 20I9)

\begin{abstract}
The modulus of elasticity has been assumed constant during the finite element (FE) analysis of CFRP reinforced real sized timbers analyzed in load test in laboratory. The latest investigations have shown that it varies significantly during the loading process. Analysis of the modulus of elasticity during the loading provides answers to several questions, by which the FE analysis can be profoundly optimized and yield more accurate estimates. Analysis has been extended to load-modulus functions of previous investigations. Specimens without reinforcement were also included in the investigations, in order to eliminate anomalies of previous measurements and to get easier comparison.
\end{abstract}

KEYWORDS: Carbon fibre reinforcement, beam, modulus of elasticity, load-bearing, fourpoint bending.

\section{INTRODUCTION}

The application of fibre reinforced plastics (FRP) for the enhancement of structural elements has a long history, including intense investigation of timber structures since the 1990s (Plevris et al. 1992). Early applications of glass fibres were later joined by carbon fibres and occasionally other materials (Theakston 1965). Since a comprehensive overview of the related literature is well beyond the scope of this study, here we only review the most relevant aspects.

Like for reinforced concrete, the application of FRP for timber have looked feasible and promising, mainly to enhance structural behaviour of sawn timber beams (Gentile et al. 2002, Fiorelli et al. 2003, Li et al. 2009) or glued laminated (glulam) beams (Gilfillan et al. 2003, Fiorelli et al. 2011, Kánnár 2014). Retrospect reinforcement of old bridges or other historic buildings is also an important field of application (Amy et al. 2004, Borri et al. 2005, Nowak et al. 2013). Reinforcement elements featuring FRP materials include mostly sheets, fabrics, rods, 
but also pultruded elements or connectors. Most typically the reinforcement is fitted to or near the tension surface of the structure, glued or embedded in grooves, etc. (Borri et al. 2005, Nowak et al. 2013, Jankowski et al. 2010, Schober et al. 2006). We mention here that a branch of research focuses on bonding between wood and reinforcement; however, it is not a common failure mode for typical applications.

Various experimental studies show that the reinforcement of timber structures yields the improvement of load-bearing capacity, stiffness, and ductility, in a wide range, most likely owing to the organic nature of wood. Most studies report an increase of capacity $20 \%$ to $50 \%$ (Gentile et al. 2002, Triantafillou et al. 1992) or sometimes higher (Li et al. 2009, Borri et al. 2005, Nowak et al. 2013), a negligible increase of stiffness (Amy et al. 2004, Buell et al 2005) or occasionally much higher (Borri et al. 2005, Fiorelli et al. 2011), and a general improvement of ductility. Numerical simulations have also been carried out for several years (Gentile et al. 2002, Li et al. 2009, Gilfillan et al. 2003, Buell et al. 2005, Kim et al. 2010, Fiorelli et al. 2011, Nowak et al. 2013). Another important aspect of the investigation of modulus of elasticity is the effect of different treatments or the anatomical variations of the wood material, for example effect of impregnation methods or knots (Komán et al. 2013, Németh et al. 2015).

Andor et al. (2015) dealt with experimenting on various amount of CFRP reinforcement on spruce timbers. The aim of the research led by the second author of this paper was to determine the increase of load-bearing capacity and stiffness of composite beams due to carbon fibre reinforcement by means of real size experiments and therefore verify the effectiveness of reinforcement via statistical analysis that gave numerical support to the reliability of the tests.

In the case of real size specimens, it becomes possible to draw conclusions from the analysis of beams fraught with wood defects. Small test specimens with wood defects are usually omitted because their size is a risk to the continuity of specimens, which is ensured by the flawless parts in the case of larger specimens, embedding the defects evolved during growth of the wood (knots, damages).

The diversity of experimental results on fibre reinforcement of timber beams highlights the significance of several factors, e.g. species, amount and material of fibres, shape and arrangement of reinforcement, size of specimens, etc. The aim of the research was to conduct experiments on timber beams reinforced with CFRP in order to assess the potential of this technique particularly with respect to solid beams made of Norway spruce, a species native and widespread in Europe (Andor et al. 2015). The reinforcement was chosen so that it was easy to apply in three different amounts along the full length. The measurements showed an increase of $18-33 \%$ of load-bearing capacity, $9-16 \%$ of stiffness, as well as $8-29 \%$ of deflection. In a project run simultaneously, we obtained similar results for beams of the same species but larger cross- sections, which supports the validity of the tests.

The increases of reinforcement data are well within the range of most results obtained for various wood species by other researchers (Fiorelli et al. 2003), however, it is important to note that values significantly higher or lower are also reported (Li et al. 2009). Species covered include several European, American, Asian, or other species. An overview of related results clearly indicates that the effectiveness of reinforcement varies in such a wide range from species to species, that it is unsafe to draw any conclusion regarding a new one. Moreover, wood material of the same species may differ significantly with respect to geographical locations. However, results reported in Andor et al. (2015) clearly make ground for further research and development of reinforced spruce beams.

A detailed statistical analysis has also been conducted in Andor et al. (2015), that has shown that the behaviour of reinforced beams was significantly affected by the quality of the wood 
material. A distinction can be made within the test specimens based on the obvious presence of knots and invisible defects, which most likely affects the potential in reinforcement. It can be observed that the strong specimens typically fail by tension of timber, while other modes like cross-graining, compression, shearing, etc. are more common in the case of weak specimens.

\section{Analysis of modulus of elasticity}

The analysis involved the bending of spruce beams with length $2000 \mathrm{~mm}$ (supported on $1800 \mathrm{~mm}$ ) and cross-section $95 \times 95 \mathrm{~mm}$. Several problems arose during the modelling of spruce beams reinforced with carbon fibre materials because of difficulties in FE simulations. During the $\mathrm{FE}$ analysis the modulus of elasticity has been assumed constant while the latest investigations have shown that it varies significantly during the loading process. Analysis of the modulus of elasticity during the loading provides answers to several questions, by which the $\mathrm{FE}$ analysis can be profoundly optimized and yield more accurate estimates.

In laboratory measurements, moduli of elasticity of timber beams were determined by measurements based on dynamic principles using non-destructive and destructive procedures. The non-destructive procedure involved an instrument called Fakopp (Divós et al. 2005), which enables the calculation of the modulus of elasticity based on the propagation speed of sound. During the destructive procedure the moduli were determined by four-point bending of the beams till failure considering deflections (Dániel 2016, Kánnár 2014).

Since the modulus of elasticity of the wood material alone could be determined for specimens both reinforced and non-reinforced, we used modified values of moduli measured for the specimens to be equivalent to $12 \%$ moisture content.

We conducted experiments for the a priori estimation of the modulus of elasticity by means of bending loading up to $5 \%$ of the ultimate load and repeating it after applying reinforcement. The results showed a mixed picture disabling any clear conclusions.

At the measurement of the modulus of elasticity we only determined average values according to respective standards, hence recording during the loading procedure was missing. We noted that the modulus of elasticity was not constant during the loading, therefore in a related collaborative study several finite element types were applied to approximate laboratory data curves (Saad 2017). We also applied a method when the modulus of elasticity was computed based on the measured deflection data, which led to surprising results.

\section{The behavior of the modulus of elasticity}

It was difficult to analyse the modulus of elasticity primarily responsible for the stiffness of the beams, partly because there was little similarity between the individual specimens, that can be attributed to the anisotropy of wood and the presence of wood defects.

The original aim of this study was to develop a finite element model that can give good estimates greatly depends on our knowledge on the behaviour of wood properties under the loading process. Using the finite element models developed during our research and the stressstrain data in the specimens we made a well applicable computational procedure. We also aimed to compute the modulus of the composite reinforcement in fibre direction (Bellovics 2016, Saad 2017). Specimens used in laboratory testing formed the bases of reference in order to make the finite element model as realistic as possible.

Thus during the first phase of modelling, the internal properties (stresses and strains) were compared with the results of laboratory measurements. This comparison was necessary to assess whether stresses and strains obtained from the finite element modelling approximated those of laboratory measurements. The conclusions were determined by the analysis particularly made for 
the laboratory measurements (Bellovics 2016) as well as the modelling procedure. The comparison has shown that the unreinforced timber could be modelled approximatively as the stress and strain data were not in full agreement (Fig. 3). In the case of reinforced specimens, the stress distribution could not be measured but only computed approximatively, though these computations did not provide the expected overall picture. Therefore, here there was no basis for comparison and we could rely only on the data obtained from the finite element computation (Fig. 1).

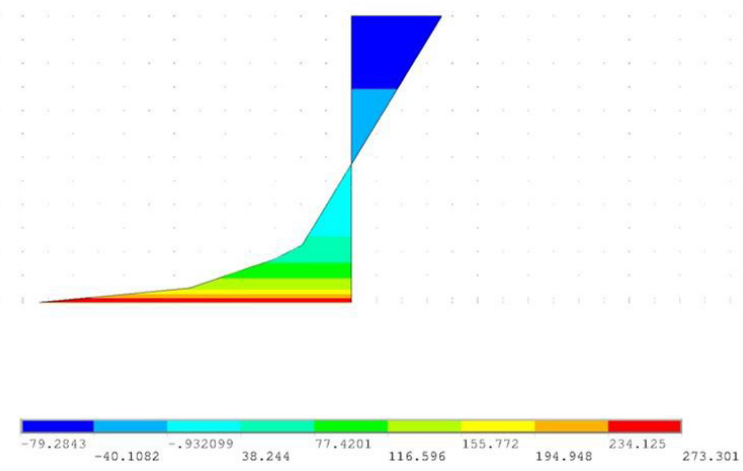

Fig. 1: Normal stress distribution along the cross section of a bended beam (95 $95 \times 2000 \mathrm{~mm})$ reinforced with 1 layer of CFRP

There were also extreme differences regarding the strains. Measurement of strains in the laboratory was performed using strain gauges, which have the disadvantage of measuring plane strains only and thus the internal distribution could only be estimated. This approach was unable to determine whether the major problem is with the model or the measurements.

\section{MATERIAL AND METHODS}

\section{Material}

Timber for the beams with $2000 \mathrm{~mm}$ length was sawn of Norway spruce (Picea abies) in rectangular solid cross-sections of $95 \times 95 \mathrm{~mm}$ with random orientation with respect to growthrings (i.e. $\mathrm{R}$ and $\mathrm{T}$ directions were not aligned with the contour of the cross-section). All specimens were dried to moisture content of $12 \%$. Via visual inspection and non-destructive tests it was ensured that the test specimens had no major visible defects or damage, such as drying splits, biological deterioration, etc. Presence of knots was allowed as a natural feature of the species.

Fibre reinforcements were prepared in situ using unidirectional ( $99 \%$ of fibres with respect to surface in warp, $1 \%$ in weft) carbon fibre fabric of $300 \mathrm{~g} \cdot \mathrm{m}^{-2}$ weight and a two-component epoxy resin of the company SIKA AG. applied manually in approximately $0.5 \mathrm{~kg} \cdot \mathrm{m}^{-2}$ amount. The epoxy resin was applied on the surface in the prescribed amount following manufacturer's instruction using rollers. The fabric was then placed and impregnated with resin completely manually such that the strengthening took place simultaneously with the bonding to the wood. The product application instructions required no clamps or any mechanical device to apply pressure because the system is designed for retrofitting for concrete or timber even in an overhead position. 


\section{Measurement set-up}

Four-point bending tests of a series of specimens have been prepared with supports of $1800 \mathrm{~mm}$ span. The geometric parameters of the beams were set to comply with the European standards regarding testing. The experiments were conducted in a laboratory accredited for timber structural testing using a standard MTS testing device with two cylinders with capacity of $250 \mathrm{kN}$ each. Load was applied by a single actuator and transmitted to the test specimens at two points via an intermediate beam of $600 \mathrm{~mm}$ span centrally aligned, see Figs. 2 and 3. Measurements of the loading and the deflection of the middle cross-section of the beam have been performed by the testing device and a video extensometer, respectively, and the data have been recorded digitally for analysis.

The investigation was supplemented with 8 beams without reinforcement in addition to the analysis in Andor et al. (2015) for the sake of easier comparison, therefore a total of sixteen nonreinforced beams were analysed. A total of fifty-two specimens were prepared, of which thirty-six with various amounts of CFRP fabric (Tab. 1).

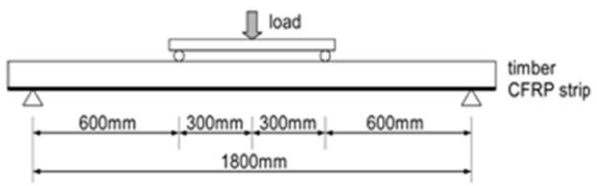

Fig. 2: Four-point bending test arrangement.

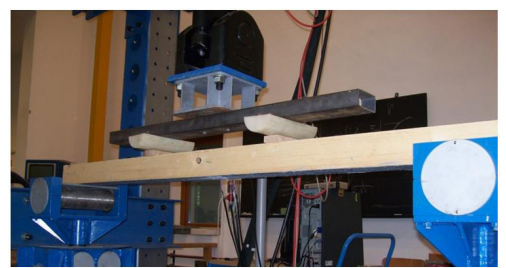

Fig. 3: Bending test arrangement and a specimen with the CFRP strip glued to the tensile face of the beam at full width.

Twenty specimens were fitted with a single and eight with a double layer of fabric on the entire width of cross-section, respectively, while the remaining eight specimens were reinforced with a narrower strip $(50 \mathrm{~mm})$ of single layer CFRP fabric centrally aligned with respect to the vertical symmetry plane (Fig. 4).

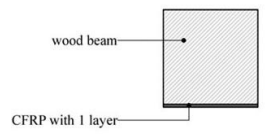

S1

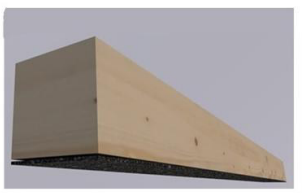

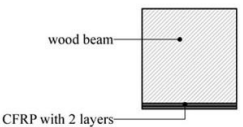

S2

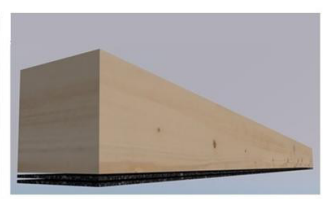

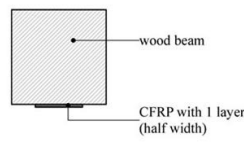

SN

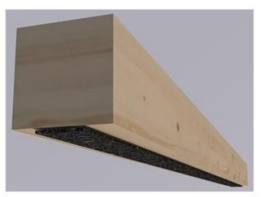

Fig. 4: Scheme of the various amount of CFRP fabric in each test group (S1, S2, SN). 
In all cases the CFRP fabric was glued to the tensile face of the beam at full length and then were cut through just near the supports. The four types of test specimens are denoted by S0, S1, $\mathrm{S} 2$, and SN, respectively. The different number of specimens in each groups were managed with statistical analysis in Andor et al. (2015). Additional specimens were also investigated to increase the amount of samples. A summary of the data are shown in Tab. 1.

The density of the wood of all specimens was measured with xilodyne device (penetration device) giving an average of $473 \mathrm{~kg} \cdot \mathrm{m}^{-3}$ with relative standard deviation of $8.5 \%$. The data were grouped and analysed with respect to the division into groups S0, S1, S2, and SN, yielding averages and relative standard deviations as $456 \mathrm{~kg} \cdot \mathrm{m}^{-3}(5.4 \%), 495 \mathrm{~kg} \cdot \mathrm{m}^{-3}(9.2 \%), 465 \mathrm{~kg} \cdot \mathrm{m}^{-3}$ (7.5\%), and $459 \mathrm{~kg} \cdot \mathrm{m}^{-3}(5.6 \%)$, respectively.

Tab. 1: Types of investigated timbers.

\begin{tabular}{|c|l|c|c|c|}
\hline Test group & Reinforcement & $\begin{array}{c}\text { Density (mean) } \\
\mathrm{kg} \cdot \mathrm{m}^{-3}\end{array}$ & Amount of CFRP & $\begin{array}{c}\text { Number of } \\
\text { specimens }\end{array}$ \\
\hline S0 & None & 456 & - & 16 \\
\hline S1 & CFRP fabric & 495 & 1 layer, full width & 20 \\
\hline S2 & CFRP fabric & 465 & 2 layers, full width & 8 \\
\hline SN & CFRP fabric & 459 & 1 layer, 50 mm width & 8 \\
\hline
\end{tabular}

They have obtained an average increase of 30\% for load-bearing and $16 \%$ for stiffness in the case of a single layer of CFRP (amount of $300 \mathrm{~g} \cdot \mathrm{m}^{-2}$ ) documented in Andor et al. 2015.

\section{Analysis of the change of the modulus of elasticity during loading}

During the laboratory testing, measurements were carried out in a way that both deflection and load values were digitally recorded every half second from the start of the loading process until failure. In order to keep track of the change of behaviour, the modulus of elasticity was computed as follows: five samples were picked out of the data series, considered five values of the load evenly spaced between zero and the ultimate load, recorded respective deflections, and finally the modulus of elasticity was computed. The deflections were also calculated using FE simulation to check accuracy.

The deflection (y) can be formulated based on the four-point bending layout as follows:

$$
y=\frac{23 \cdot F \cdot l^{3}}{1296 \cdot E \cdot I} \quad(\mathrm{~m})
$$

from which the modulus of elasticity is obtained:

$$
E=\frac{23 \cdot F \cdot l^{3}}{1296 \cdot y \cdot I} \quad\left(\mathrm{~N} \cdot \mathrm{m}^{-2}\right)
$$

where: $\quad F-$ load (concentrated) $(\mathrm{N})$,

$l-\operatorname{span}(\mathrm{m})$,

$I$ - moment of inertia for bending axis $\left(\mathrm{m}^{4}\right)$.

This procedure was performed for several timber specimens, as well as reinforced specimens. The data have revealed that the modulus of elasticity varied during the loading process, therefore we examined the modulus of elasticity during the entire process for all the test specimens considered in (Andor et al. 2015), as well as they were supplemented with additional nonreinforced timber beams to enables a more indirect comparison. 


\section{RESULTS AND DISCUSIONS}

Modulus of elasticity against load is plotted for non-reinforced beams, for reinforced beams with 1 layer, for reinforced beams with 2 layers, and for reinforced beams with half layer in Figs. 5 to 8, respectively.

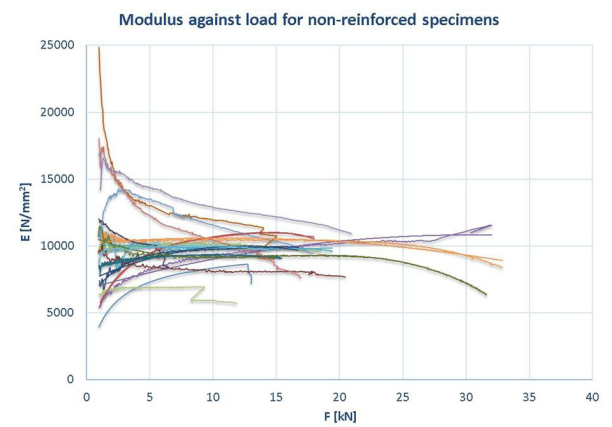

Fig. 5: Modulus of elasticity against load for nonreinforced beams.

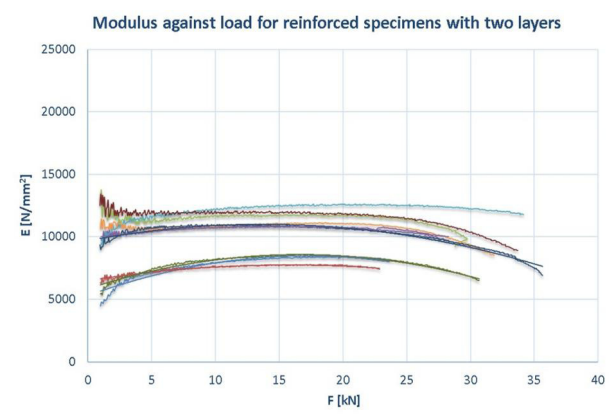

Fig. 7: Modulus of elasticity against load for reinforced beams with 2 layers.

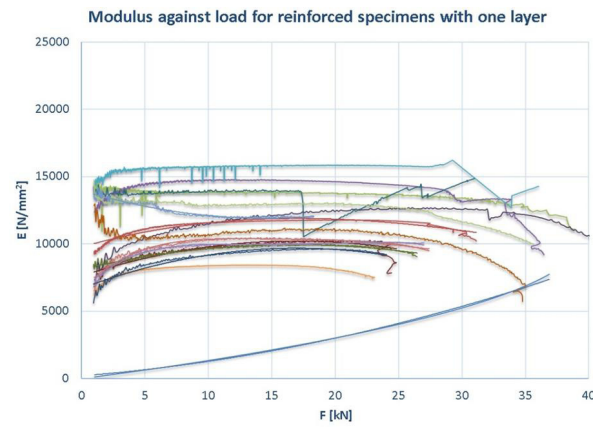

Fig. 6: Modulus of elasticity against load for reinforced beams with 1 layer.

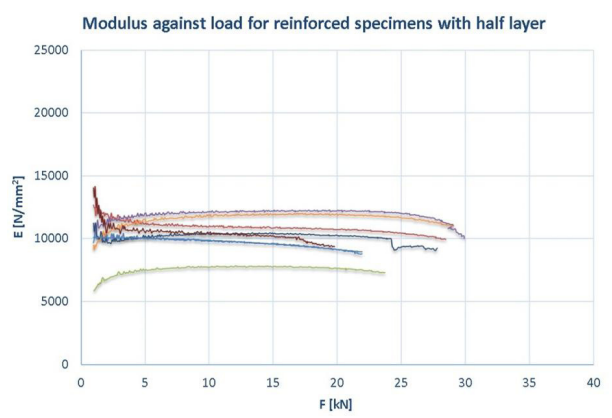

Fig. 8: Modulus of elasticity against load for reinforced beams with half layer.

Characteristic values of the modulus of elasticity were computed at abscissas where the settlement of the specimens under loading had already taken place. For reinforced specimens it was set to $20 \mathrm{kN}$, while for non-reinforced ones it was only $15 \mathrm{kN}$ due to early failure.

Consequently, the characteristic average modulus of elasticity for each specimen group was obtained as $9622 \mathrm{MPa}(\mathrm{S} 0), 11572 \mathrm{MPa}$ (S1), $10366 \mathrm{MPa}$ (S2), $10183 \mathrm{MPa}$ (SN), respectively, which correlate with other studies analyzing modulus of elasticity of CRP reinforced wooden construction elements (Fiorelli et al. 2003, Fedyukov et al. 2017, Togay et al. 2017, Essert et al. 2018).

The diagrams show that the modulus of elasticity of wood within the effective load-bearing range varies significantly from specimen to specimen, all in positive, negative, and mixed directions. It can also be noted that the initial sections (up to approx. $7 \mathrm{kN}$ ) of the curves are variable because the specimens have not settled yet under the load. Incidental torsion or skewness resulting in non-ideal situation of the beam on the supports may have their influence in this 
phase, but then beyond this the stretching of the beam leads to a relatively pure bending until failure.

It is quite apparent that the behavior of wood is characteristic to fibre bundle systems exhibiting imperfections (knots, loose end fibres). Failures of individual fibre bundles can be observed as well as activation of new bundles. Larger jumps are due to disturbances of videoextensometer used for measuring the deflections (e.g. sudden changes in lighting).

In the case of reinforced specimens, the settlement phase is shorter $(5 \mathrm{kN})$, beyond that the modulus of the composite beam is more or less constants, and starts declining at the end.

\section{CONCLUSIONS}

1. Typical value of the modulus of elasticity for the non-reinforced timber beams is $19244 \mathrm{MPa}$.

2. Carbon fibre reinforcement is active all the time of the loading, and there is no distinguishable finite phase that might mark the start of its contribution to load-bearing.

3. CFRP applied to timber beams continuously contributed to load-bearing.

4. The curve of the modulus of elasticity enables to predict failure.

5. The modulus of elasticity is constant within the effective load-bearing range of reinforced beams that have large load-bearing capacity.

6. Typical value of the modulus of elasticity for beams reinforced with a single layer is $23144 \mathrm{MPa}$.

7. Typical value of the modulus of elasticity for beams reinforced with a double layer is $20733 \mathrm{MPa}$.

8. Typical value of the modulus of elasticity for beams reinforced with a half layer is $20365 \mathrm{MPa}$.

In terms of further potential research, it is necessary to do a full statistical and function analysis on the new load-modulus diagrams, which goes beyond the scope of this paper. It would be preferable to perform similar analysis also on the finite element models in the future. In addition it is recommended to make similar analysis with Glu-Lam beams (Kánnár 2014).

\section{ACKNOWLEDGEMENTS}

The described work was carried out as part of the 'Roadmap for Structural Changes of the University of Sopron' - nr. 32388-2/2017 INTFIN. The Ministry of Human Capacities of the Hungarian Government supported the realization of this project. The additional investigations of specimens were carried in the frame of the „EFOP-3.6.1-16-2016-00018 - Improving the role of research+development+innovation in the higher education through institutional developments assisting intelligent specialization in Sopron and Szombathely".

We wish to thank to SIKA AG. for providing the materials for CFRP reinforcement to complete this project. 


\section{REFERENCES}

1. Amy, K., Svecova, D., 2004: Strengthening of dapped timber beams using glass fibre reinforced polymer bars. Canadian Journal of Civil Engineering 31 (6): 943-955.

2. Andor, K., Lengyel, A., Polgár, R., Fodor, T., Karácsonyi, Z., 2015: Experimental and statistical analysis of spruce timber beams reinforced with CFRP fabric. Construction and Building Materials 99 (8): 200-207.

3. Bellovics, B., 2016: FEM Analysis of CFRP reinforced timber. MSc thesis. (In Hungarian) University of West Hungary, $50 \mathrm{p}$.

4. Borri, A., Corradi, M., Grazini, A., 2005: A method for flexural reinforcement of old wood beams with CFRP materials. Compos. Part B 36 (2): 143-153.

5. Buell, T.W., Saadatmanesh, H., 2005: Strengthening timber bridge beams using carbon fibre. Journal of Structural Engineering 131 (1): 173-187.

6. Dániel, B., 2016: Utilization of CFRP reinforced wood beam. BSc Thesis. University of Sopron, 46 pp.

7. Divós, F., Tanaka, T., 2005: Relation between static and dynamic modulus of elasticity of wood. Acta Silvatica et Lignaria Hungarica (1): 105-110.

8. Essert, S., Rede, V., Svagelj, Z., 2018: The bending modulus of elasticity of subfossil elm wood. Wood Research 63 (2): 239-248.

9. Fedyukov, V., Saldaeva, E, Chernova, M., 2017: Different ways of elastic modulus comaritive study to predict resonant properties of standing spruce wood. Wood Research 62 (4): 607-614.

10. Fiorelli, J., Dias, A.A., 2011: Glulam beams reinforced with FRP externally-bonded: theoretical and experimental evaluation. Materials and Structures 44 (8): 1431-1440.

11. Fiorelli, J., Dias, A.A., 2003: Analysis of the strength and stiffness of timber beams reinforced with carbon fiber and glass fiber. Materials Research 6 (2): 193-202.

12. Gentile, C., Svecova, D., Rizkalla, S.H., 2002: Timber beams strengthened with GFRP bars: development and applications. Journal of Composites for Construction 6 (1): 11-20.

13. Gilfillan, J.R., Gilbert, S.G., Patrick, G.R.H., 2003: The use of FRP composites in enhancing the structural behaviour of timber beams. Journal of Reinforced Plastics and Composites 22 (15): 1373-1388.

14. Kánnár, A., 2014: Evaluation of glulam beams' performance in special environmental conditions. Wood Research 59 (5): 803-812.

15. Kim, Y.J., Harries, K.A., 2010: Modeling of timber beams strengthened with various CFRP composites. Engineering Structures 32: 3225-3234.

16. Komán, Sz., Fehér, S., Ábrahám, J., Taschner, R., 2013: Effect of knots on the bending strength and the modulus of elasticity of wood. Wood Research 58 (4): 617-626.

17. Jankowski, L.J., Jasienko, J., Nowak, T.P., 2010: Experimental assessment of CFRP reinforced wooden beams by 4 - point bending tests and photoelastic coating technique. Materials and Structures 43: 141-150.

18. Li, Y.F., Xie, Y.M., Tsai, M.J., 2009: Enhancement of the flexural performance of retrofitted wood beams using CFRP composite sheets. Construction and Building Materials 23 (1): 411-422.

19. Molnár, S., Varga, F., Fehér, S., Németh, R. 2000: Technical parameters of Norway spruce. Handbook of wood technology, Vol. I., Pp 34-88.

20. Németh, R., Tsalagkas, D., Bak, M., 2015: Effect of soil contact on the modulus of elasticity of beeswax-impregnated wood. BioResources 10 (1): 1574-1586. 
21. Nowak, T.P., Jasienko J., Czepizak, D., 2013: Experimental tests and numerical analysis of historic bent timber elements reinforced with CFRP strips. Construction and Building Materials 40: 197-206.

22. Plevris, N., Triantafillou, T.C., 1992. FRP reinforced wood as structural material. Journals of Materials in Civil Engineering 4 (3) 300-317.

23. Saad, K., 2017: Finite element modeling of timber beams reinforced with CFRP. MSc Thesis. Budapest University of Technology, 119 pp.

24. Schober, K.U., Rautenstrauch, K., 2006: Post-strengthening of timber structures with CFRP's. Materials and Structures 40: 27-35.

25. Theakston, F.H.,1965. A feasibility study for strengthening timber beams with fiberglass. Canadian Agricultural Engineering, Pp 17-19.

26. Togay, A., Döngel, N. , Sögütlü, C., Ergin, E., Uzel, M., Günes, S., 2017: Determination of the modulus of elasticity of wooden construction elements reinforced with fiberglass wire mesh and aluminium wire mesh. BioResources 12 (2): 2466-2478.

27. Triantafillou ,T.C. , N. Deskovic, 1992: Prestressed FRP sheets as external reinforcement of wood members. Journal of Structural Engineering 118 (5): 1270-1284.

\author{
Krisztián Andor*, Bertalan Bellovics \\ UNIVERSITY OF SOPRON \\ Faculty Simonyi Károly of Technics Wood Science and Art \\ Institute For Applied Mechanics and Structures \\ 9400 Sopron \\ BAJCSY-Zs. E. U. 4. \\ Hungary \\ *Corresponding author: andor.krisztian@uni-sopron.hu
}

